\section{ECCOMAS}

Proceedia

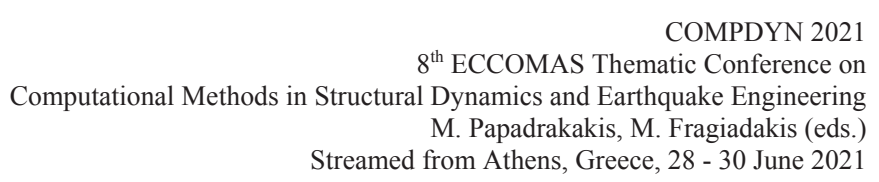

\title{
SEISMIC RESPONSE OF INNOVATIVE CFS WALLS BRACED WITH UHS STEEL BARS: EXPERIMENTAL INVESTIGATION
}

\author{
Alessia Campiche ${ }^{1}$ \\ ${ }^{1}$ Department of Structures for Engineering and Architecture, University of Naples "Federico \\ II", Italy \\ e-mail: alessia.campiche@unina.it
}

\begin{abstract}
Advantages of Cold Formed Steel (CFS) structures are now well known all over the world. The new goal is represented by the improvement of structural performances, in order to build higher and safer constructions in seismic area. To this aim, in the framework of an Italian project in cooperation with Lamieredil S.p.A. company, the University of Naples "Federico II" developed a new Lateral Force Resisting System (LFRS), made of CFS frame braced by Ultra High Strength (UHS) steel bars in " $V$ " configuration. Three different configurations of the LFRS, with increasing lateral capacities, were designed, and tested under monotonic and reversed cyclic load protocols at the Lab of the Department of Structures for Engineering and Architecture. In total, five tests on full scale $2400 \times 2800 \mathrm{~mm}_{2}$ (length $x$ height) were carried out. The paper provides all the details on the full-scale wall tests and discusses the obtained results. Moreover, a test-based evaluation of behaviour factor is presented.
\end{abstract}

Keywords: LWS system, CFS structure, Seismic behaviour, Full-scale test, Behaviour factor.

ISSN:2623-3347 @ 2021 The Authors. Published by Eccomas Proceedia.

Peer-review under responsibility of the organizing committee of COMPDYN 2021.

doi: $10.7712 / 120121.8777 .19381$ 


\section{INTRODUCTION}

Many Italian reaserch projects, numerical and analytical studies demonstrated the ability of steel systems to show very good structural [1-16].

The increasing market demand for high-performance and low-cost constructions oriented the choice of the last decades to a competitive and ecofriendly solution: Lightweight Steel (LWS) systems made of Cold-Formed Steel (CFS). In this field the University of Naples "Federico II" was really active [17-25] and in this perspective an Italian Research Project, named as ECCEISA [1], has recently finished, in which the main aim was the development of an innovative LWS system with higher structural, energetic and environmental performances. The core of the project was the evaluation of seismic and thermal performances of a wall system braced with pre-tensioned Ultra-High-Strength (UHS) steel bars.

The innovative wall system is mainly composed of: (1) UHS steel bracing; (2) pre-tensioning devices; (3) chord studs; (4) tracks; (5) hold-downs; (6) blocking profiles and flat straps.

The UHS steel bracing consists of two diagonal braces, which are pretensioned dog bone shaped round bars having thread ends to allow their connection and pre-tensioning. For the chord studs, a back-to-back $\mathrm{C}$ section was selected, while for tracks a box section was chosen. The pre-tensioning device is a $U$ shape profile con-nected to the hold-down through a cylindrical hinge, which allows the rotation in the plane of the wall.

A UHS steel (fy=1300 MPa, fu=1450 MPa) is adopted for the diag-onal braces, while chord studs, tracks, blocking and flat straps are made of S280 $\mathrm{GD}+\mathrm{Z}$ steel grade, and devices for pre-tensioning and hold-downs are made of S355 steel grade (fy=355 MPa, fu=470 MPa). More details about the innovative wall and the design phase are available in [26].

The effectiveness and the limitations of the innovative wall system were validated through an extensive experimental campaign carried out at Laboratory of the Department of Structures for Engineering and Architecture of University of Naples "Federico II", which consisted of small-scale tests on materials and nut-bar assemblies and full-scale wall tests. This paper describes in details the full-scale wall tests and the obtained results.

\section{EXPERIMENTAL TESTS}

The main core of the research project was the evaluation of seismic behaviour of the innovative wall system. To this purpose, five tests, including three monotonic tests and two cyclic tests, were carried out on full-scale $2400 \mathrm{~mm}$ long and $2800 \mathrm{~mm}$ high wall specimens. Two configurations of the innovative wall system have been investigated, which were representative of Light (L) and Medium (M) configurations developed. The label defines the specimen typology. Namely, the first letter indicates the test typology ( $\mathrm{M}$ for monotonic test and $\mathrm{C}$ for reversed cyclic test), the second letter is referred to the wall specimen ( $\mathrm{L}$ for specimen representative of Light configuration and $\mathrm{M}$ for specimen representative of Medium configuration) and the number represents the test number; e.g. M L1 means the monotonic test no. 1 carried out on the specimen representative of the Light wall configuration. Both configu- 
ration specimens are represented in Figure 1. In both configurations and for both protocols used, the bars were pre-tensioned before starting the test via a torque wranch.

The test program is summarized in Table 1, in which the load type, loading protocol and number of tests are shown.

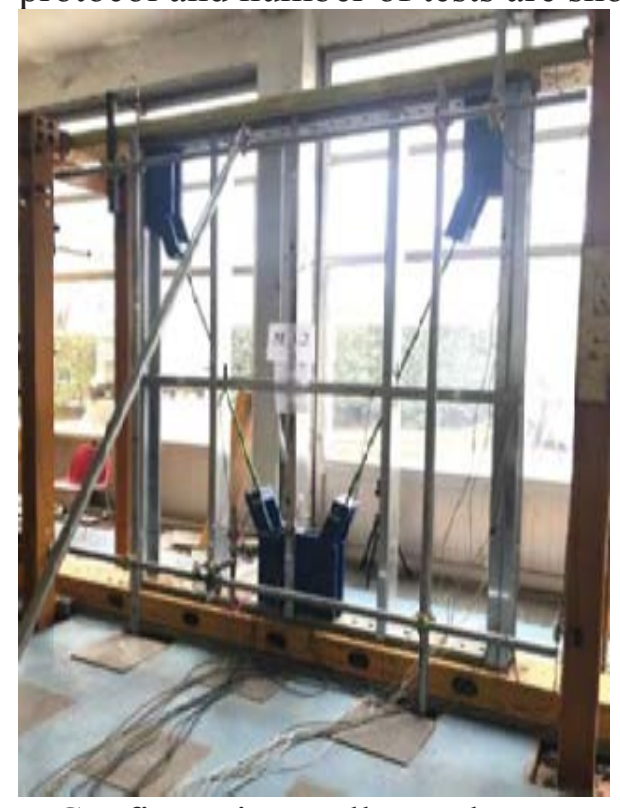

L Configuration wall tested

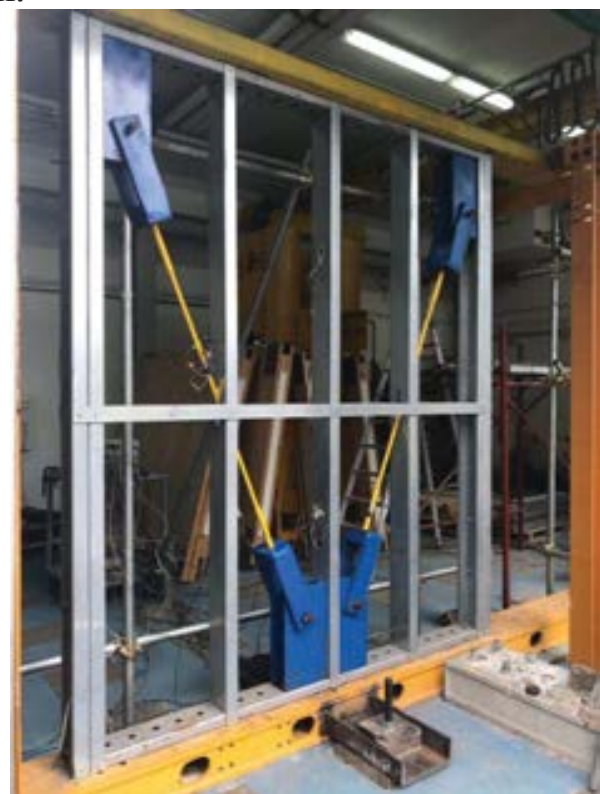

M Configuration wall tested

Figure 1 Specimen tested

Table 1 Test matrix for the monotonic and cyclic tests on full-scale walls

\begin{tabular}{cllll}
\hline $\begin{array}{c}\text { Test La- } \\
\text { bel }\end{array}$ & Wall type & $\begin{array}{c}\text { Load } \\
\text { Type }\end{array}$ & Protocol & $\begin{array}{c}\text { Num- } \\
\text { ber of } \\
\text { tests }\end{array}$ \\
\hline M_L & Light & Monotonic & - & 2 \\
\hline M_M & Medium & Monotonic & - & 1 \\
\hline C_L & Light & Cyclic & CUREE & 1 \\
\hline C_M & Medium & Cyclic & CUREE & 1 \\
\hline
\end{tabular}

An available steel frame set-up for in-plane wall tests was modified and used for the experimental activity (Figure 2). The wall prototype was restrained to the laboratory strong floor by the bottom beam, which has a $300 \times$ $180 \times 30$ (width $\times$ height $\times$ thickness) rectangular hollow section. Horizontal loads were transmitted to the wall through the loading beam, which has a 200 $\times 120 \times 10 \mathrm{~mm}$ (width $\times$ height $\times$ thickness) rectangular hollow section. The out-of-plane displacements of the wall were restrained by two steel portal frames equipped with roller wheels. The tests were performed by using a hydraulic actuator having a stroke displacement of $500 \mathrm{~mm}$ and a load capacity of $500 \mathrm{kN}$. A sliding-hinge was placed between the loading actuator and the loading beam, in order to avoid vertical load components. 


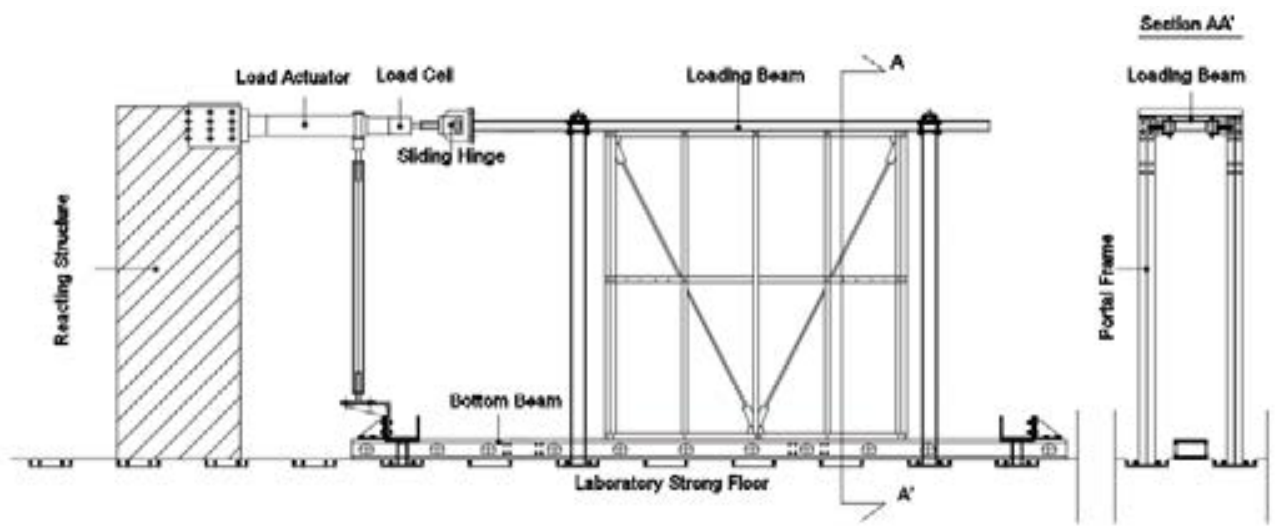

Figure 2 Wall test set-up

Six LVDTs and two potentiometers were used to measure the specimen displacements. In particular, three LVDTs (L1, L2 and L3) were installed to record hold-down horizontal and vertical displacements, two LVDTs (L4 and L5) for the upper beam vertical displacements, one LVDT (L6) for wall vertical displacements and two potentiometers (P1 and P2) for wall horizontal displacements. The strains in selected points of the diagonal bars and studs were recorded by means of fourteen strain-gauges. Two strain-gauges were installed on each diagonal (SG1 and SG2 placed near the middle section, where the diameter is reduced, and SG3 and SG4 placed where the section is maximum), four strain gauges were placed on the intermediate stud in two sections (SG5 and SG6 placed on the upper section, SG7 and SG8 on the lower section) and six strain gauges were placed on the right chord stud (SG9, SG10 and SG11 placed on the upper section and SG12, SG13 and SG14 placed on the lower section). The instrumentation pictures are shown in Figure 3. A load cell was used to measure the applied loads.

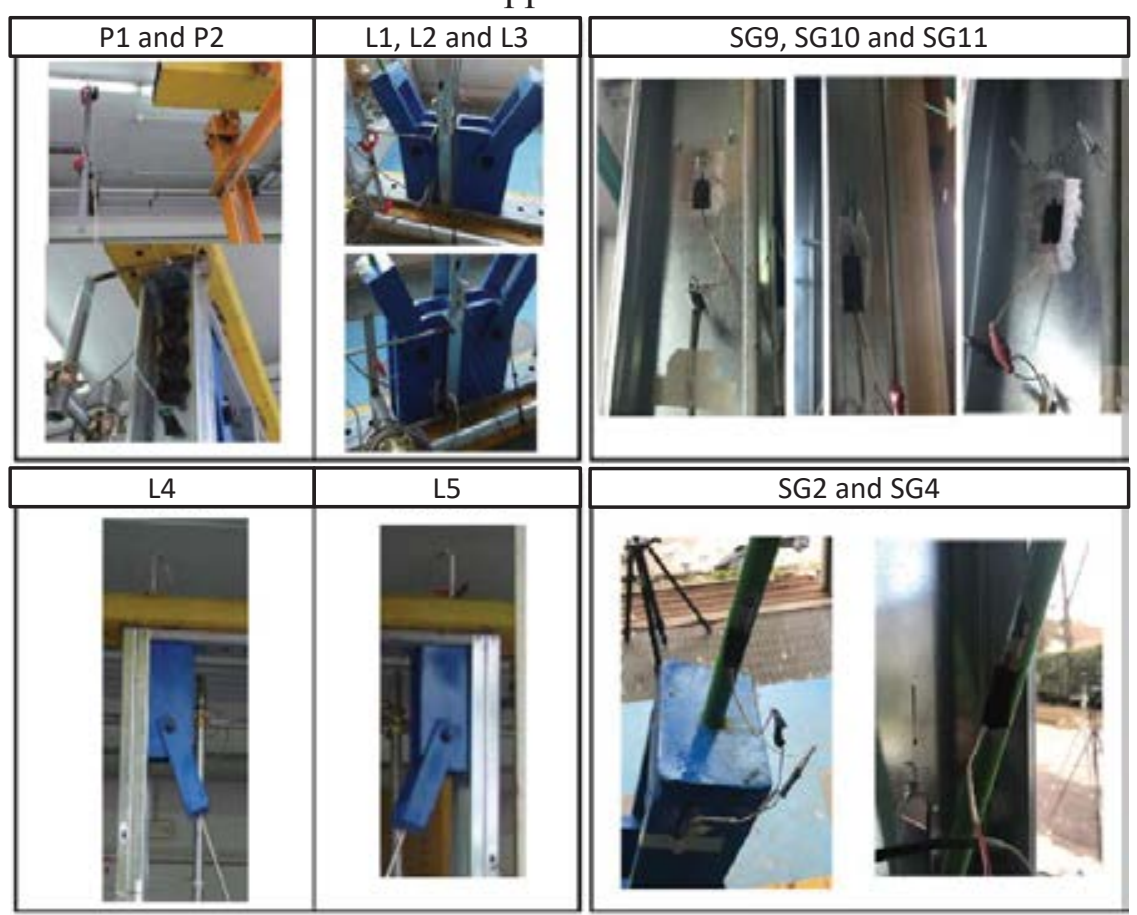

Figure 3 Photographs of wall test instrumentation 


\subsection{Monotonic tests}

Monotonic tests were carried out with displacements imposed at a rate of $0.10 \mathrm{~mm} / \mathrm{s}$ until the collapse of specimens occurred. The data were recorded with a sampling frequency equal to $10 \mathrm{~Hz}$.

Three monotonic tests were carried out on two L and one M walls. Results for M_L2 and M_L1 specimens are provided in Errore. L'origine riferimento non è stata trovata., in term of load $(\mathrm{H})$ vs. inter-storey drift ratio $(\mathrm{dr})$ curves. The displacements used for the evaluation of inter-storey drifts were measured by potentiometer P1, whereas load was provided by load cell.

Numerical values are provided in Table 2, according to the following parameters:

- $\quad \mathrm{H}_{0}$ : wall strength corresponding to the end of the Phase (1);

- $\mathrm{H}_{\mathrm{e}}$ : wall conventional yield strength evaluated according to ECCS procedure [9];

- $\quad \mathrm{H}_{\mathrm{y}}$ : wall strength corresponding to the end of the Phase (2);

- $\quad \mathrm{H}_{\mathrm{p}}$ : maximum recorded load corresponding to the end of the Phase (3);

- $\quad \mathrm{d}_{\mathrm{e}}$ : yield displacement evaluated according to ECCS procedure [27];

- $\mathrm{d}_{\max }$ : maximum displacement, evaluated in correspondence of $\mathrm{H}_{\mathrm{p}}$

- $\quad d_{r, e}$ : yield inter-storey drift ratio, equal to $d_{e} / h$;

- $d_{r, \text { max }}$ : maximum inter-storeydrift ratio, equal to $d_{\max } / h$;

- $\quad \mathrm{k}_{\mathrm{e}}$ : initial elastic stiffness corresponding to the tangent to initial part of the response curve, equal to $\mathrm{H}_{\mathrm{e}} / \mathrm{d}_{\mathrm{e}}$;

- $\quad \mu$ : ductility, equal to the ratio between the conventional ultimate displacement and displacement at conventional elastic limit load $\mathrm{d}_{\max } / \mathrm{d}_{\mathrm{e}}$ or equally $\mathrm{d}_{\mathrm{r}, \text { max }} / \mathrm{d}_{\mathrm{r}, \mathrm{e}}$.

Globally, for all the specimens the monotonic response showed a threephase lateral behaviour. In particular, the curves are characterized by three different branches: (1) the first linear branch with a stiffness $\mathrm{k}_{\mathrm{e}}$; (2) once achieved $\mathrm{H}_{0}$, the second branch characterised by a linear response having a stiffness smaller than $\mathrm{k}_{\mathrm{e}}$; (3) once achieved $\mathrm{H}_{\mathrm{y}}$, the third branch characterised by a nonlinear response.

M_L2 and M_M1 specimens showed the same collapse due to the tension failure of the bar, whereas in M_L1 specimen, during the phase (3), nut failure happened, since only one 12 property Class nut was employed. The collapse mechanism observed in M_L2 test is provided in Figure 5. Comparing the results of two nominal identical tests, M_L1 and M_L2, can be noticed that:

- $\quad$ small differences in terms of $\mathrm{H}_{\mathrm{y}}$ and $\mathrm{H}_{\mathrm{p}}$ were revealed, equal to about $3 \%$ and $1 \%$, respectively;

- high differences in term of inter-storey drift ratios achieved were registered, equal to about 19 and $51 \%$ for $d_{r, e}$ and $d_{r, m a x}$, respectively, since the M_L1 showed a brittle nut failure. 


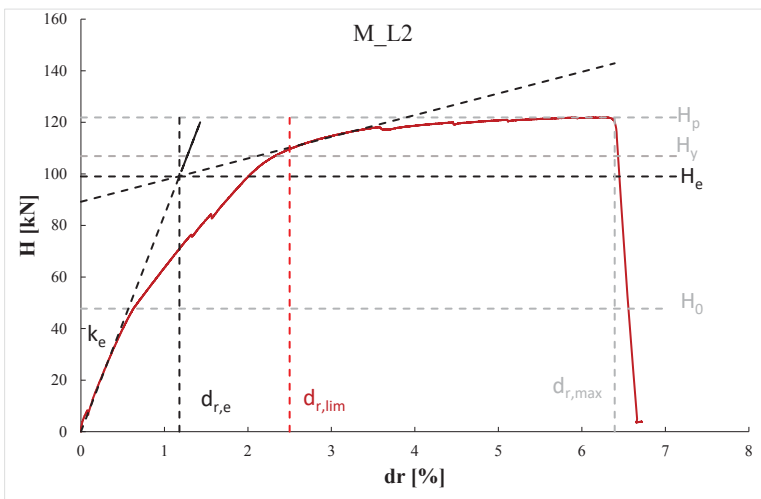

Results of M_L2 test

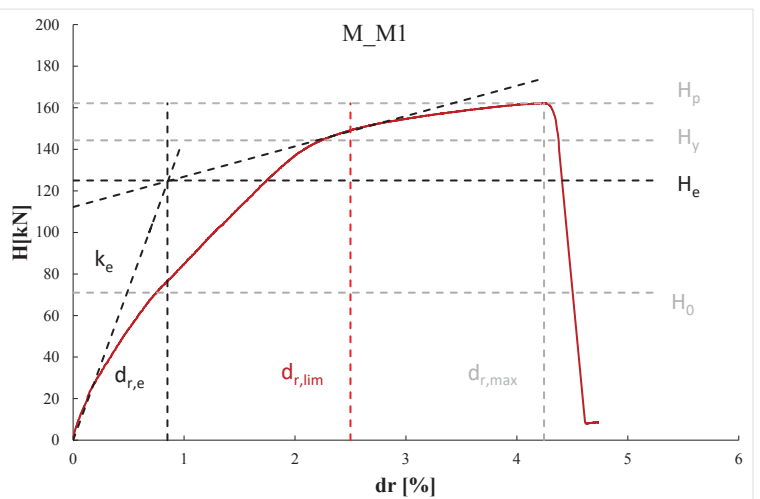

Results of M_M1 test

Figure 4 Results of M_L2 and M_M1 tests
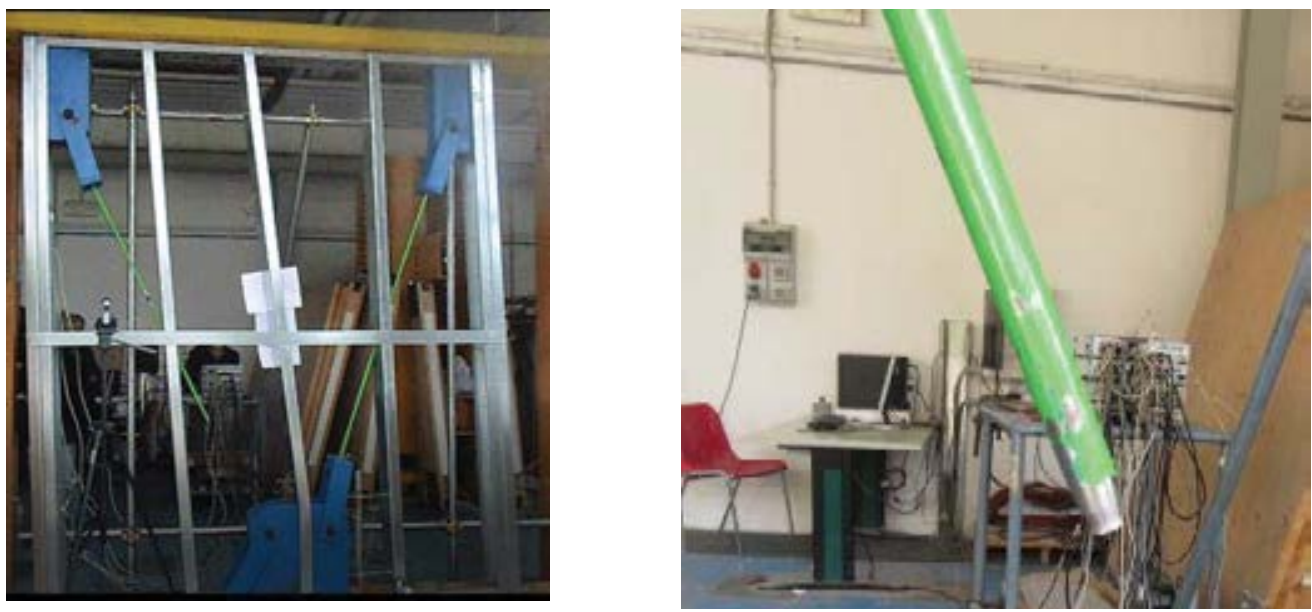

Figure 5 M_L2 test: collapse mechanism

Table 2 Monotonic test results

\begin{tabular}{|c|c|c|c|}
\hline Test & M_L1 & M_L2 & M_M1 \\
\hline $\mathrm{H}_{0}[\mathrm{kN}]$ & $\begin{array}{l}37.99 \\
100.0\end{array}$ & 47.73 & 71.01 \\
\hline $\mathrm{H}_{\mathrm{e}}[\mathrm{kN}]$ & $\begin{array}{l}0 \\
103.9\end{array}$ & 99.00 & 125.00 \\
\hline $\mathrm{H}_{\mathbf{y}}[\mathrm{kN}]$ & $\begin{array}{l}9 \\
120.5\end{array}$ & 106.90 & 144.32 \\
\hline $\mathbf{H}_{\mathrm{p}}[\mathrm{kN}]$ & 4 & 121.89 & 162.18 \\
\hline$\underset{d_{\max }}{d_{\mathrm{e}}[\mathrm{mm}]}$ & 26.60 & 33.04 & 23.80 \\
\hline [mm] & 87.21 & 179.01 & 118.86 \\
\hline $\begin{array}{c}d_{r, e}[\%] \\
d_{r, \max }\end{array}$ & 0.95 & 1.18 & 0.85 \\
\hline $\begin{array}{r}{[\%]} \\
\mathbf{k}_{\mathbf{e}}\end{array}$ & 3.11 & 6.39 & 4.25 \\
\hline$[\mathrm{kN} / \mathbf{m m}]$ & 3.76 & 3.00 & 5.25 \\
\hline$\mu[-]$ & 3.28 & 5.42 & 4.99 \\
\hline
\end{tabular}




\subsection{Reversed cyclic tests}

Cyclic tests were carried out by adopting a loading protocol known as "CUREE ordinary ground motions reversed cyclic load protocol" developed for wood walls by Krawinkler et al. [28], modified according to the prescription given in Velchev et al. [29]). The general cyclic protocol is summarized in Figure 6. Since $\Delta$ obtained from monotonic results was not really different between $\mathrm{L}$ and $\mathrm{M}$ configuration, the same specific protocol was adopted for both C_L1 and C_M1 tests.

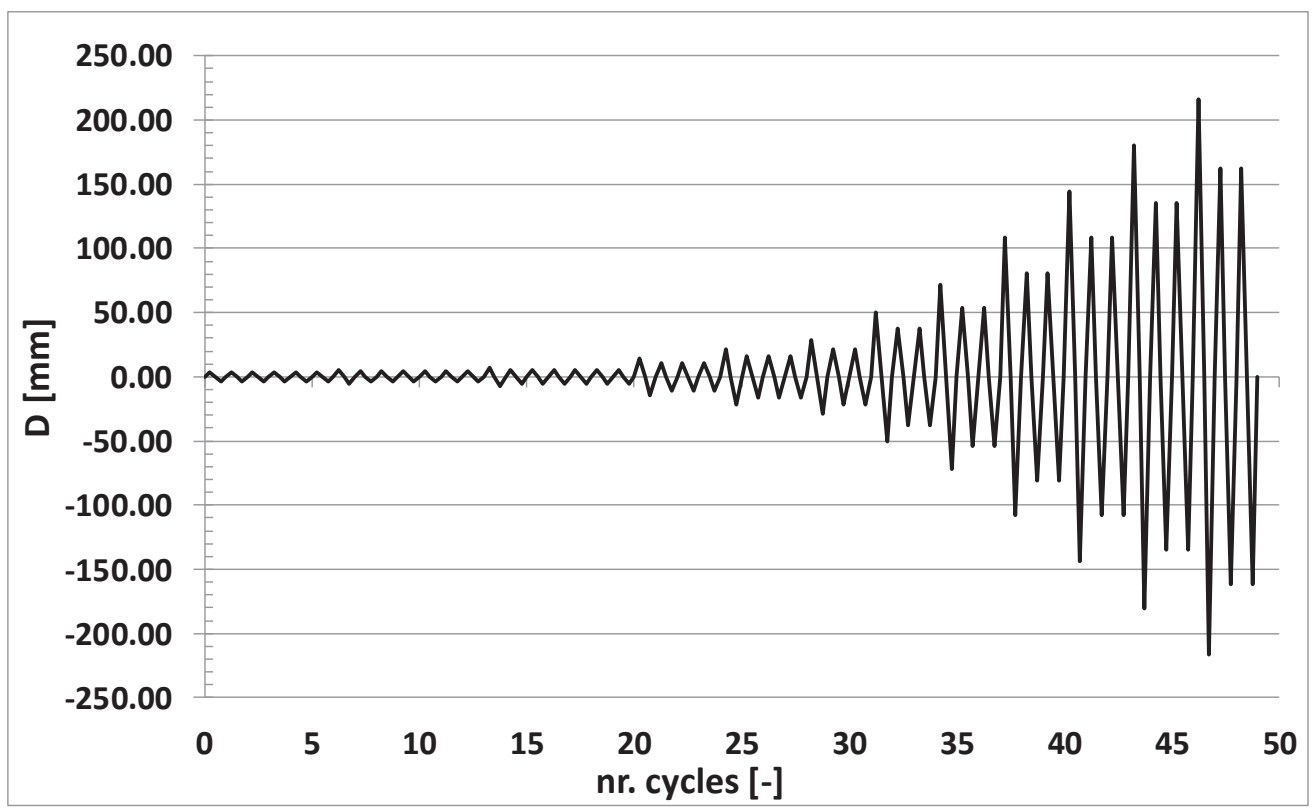

Figure 6 CUREE cyclic protocol adopted for C_L1 and C_M1 tests

The cyclic curves obtained (Figure 7) showed a behaviour rather symmetrical. The three-phase behaviour also characterized the cyclic response, but only in pushing. In fact, for both specimens collapse happened immediately reached the Phase (3) in pushing (positive range), whereas in pulling (negative range) the Phase (3) was not reached. Table 3 summarizes numerical results obtained. Both $\mathrm{C}_{-} \mathrm{L} 1$ and $\mathrm{C}_{-} \mathrm{M} 1$ specimens had the same collapse due to the tension failure of the bar, as shown in Figure 8.

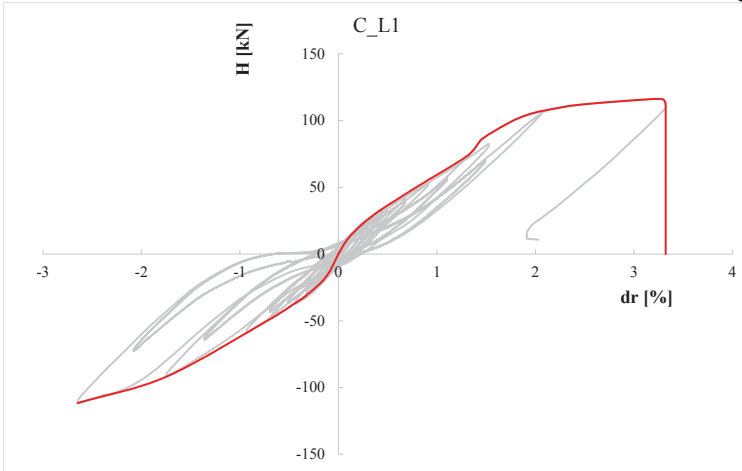

Cyclic response for C_L1 test

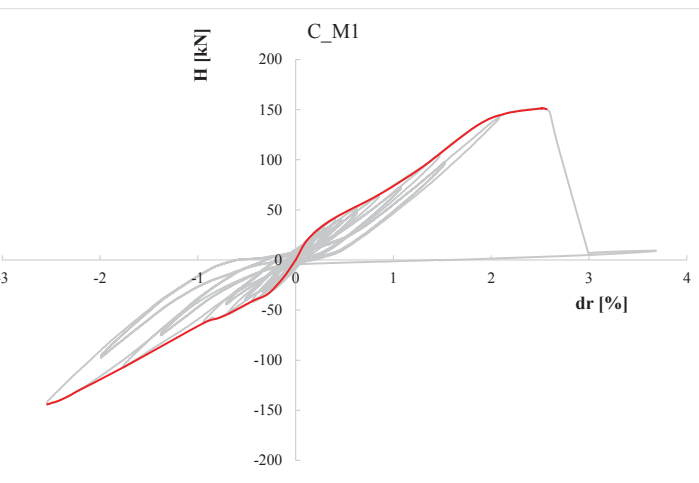

Cyclic response for C_M1 test

Figure 7 Cyclic responses obtained 
Table 3 Cyclic test results

\begin{tabular}{|c|c|c|}
\hline Test & $\mathrm{C}_{-}$ & $\mathrm{C}_{-}$ \\
& 22. & 21. \\
$\mathbf{H}_{\mathbf{0}}[\mathbf{k N}]$ & 00 & 00 \\
& 90. & 12 \\
$\mathbf{H}_{\mathbf{e}}[\mathbf{k N}]$ & 00 & 8.00 \\
& 86. & 14 \\
$\mathbf{H}_{\mathbf{y}}[\mathbf{k N}]$ & 75 & 6.22 \\
& 11 & 15 \\
$\mathbf{H}_{\mathbf{p}}[\mathbf{k N}]$ & 6.24 & 1.40 \\
& 25. & 24. \\
$\mathbf{d}_{\mathbf{e}}[\mathbf{m m}]$ & 76 & 36 \\
$\mathbf{d}_{\mathbf{m a x}}$ & 70. & 71. \\
{$[\mathbf{m m}]$} & 60 & 84 \\
& 0.9 & 0.8 \\
$\mathbf{d}_{\mathbf{r}, \mathbf{e}}[\mathbf{\%}]$ & 2 & 7 \\
$\mathbf{d}_{\mathbf{r}, \mathbf{m a x}}$ & 3.3 & 2.5 \\
{$[\mathbf{\%}]$} & 2 & 7 \\
$\mathbf{k}_{\mathbf{e}}$ & 3.4 & 5.2 \\
{$[\mathbf{k N} / \mathbf{m m}]$} & 9 & 5 \\
$\mu[-]$ & 3.6 & 2.9 \\
$\boldsymbol{H}$ & 1 & 5 \\
\hline
\end{tabular}
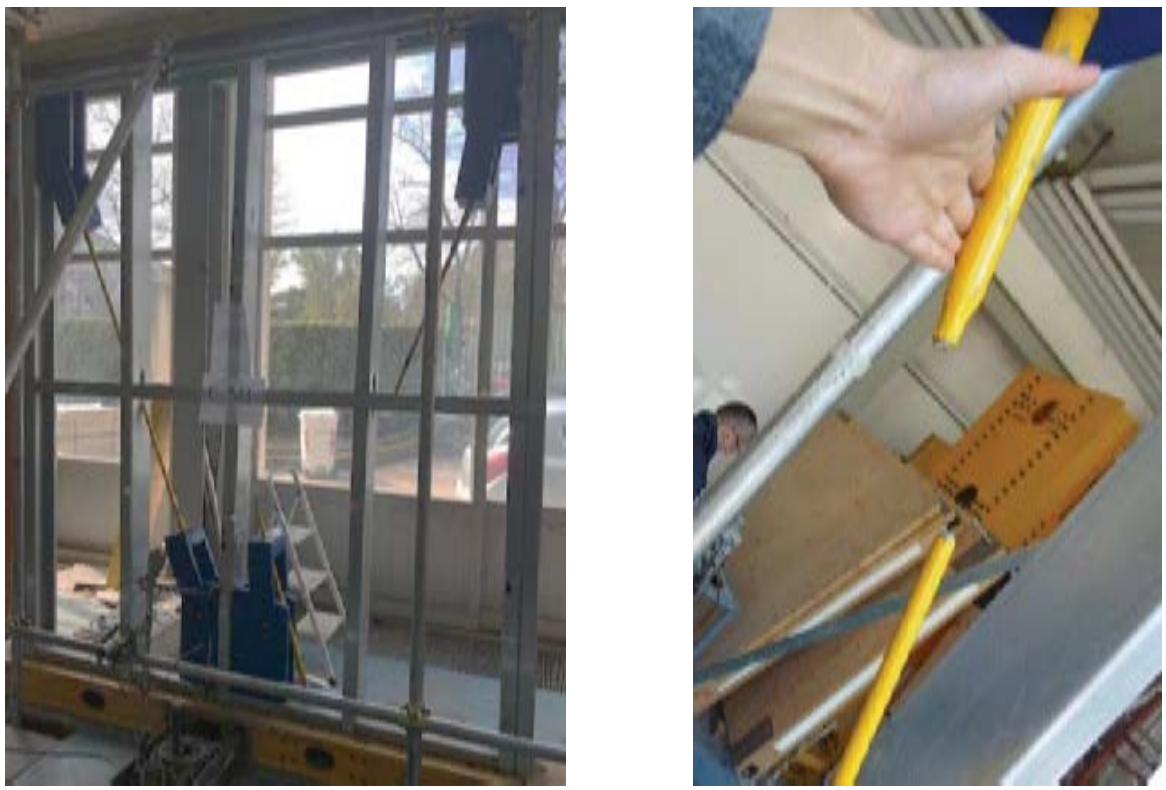

Figure 8 C_M1 test: collapse mechanism

\subsection{Discussion of results}

The global behaviour of the innovative wall was evaluated through the measurements obtained during monotonic and cyclic tests. Thanks to potentiometers P1 and P2 the wall lateral behaviour was individuated. More considerations can be done, if a comparison between monotonic and cyclic results of nominally identical specimens (Figure 9) is conducted and, in particular, considering M_L2 and M_M1 as monotonic tests and C_L1 and C_M1 as cyclic 
tests. Results of M_L1 were not considered, since it showed nut failure, instead of tension collapse of bar. It can be observed that:

- Cyclic protocol does not affect greatly the resistance of wall, in fact, monotonic and cyclic $\mathrm{H}_{\mathrm{p}}$ difference is equal to about $5 \%$ and $7 \%$ for $\mathrm{L}$ and $\mathrm{M}$ configuration, respectively;

- Cyclic protocol greatly affects the displacement capacity of wall, indeed the ductility of wall. In fact, difference in term of $d_{r, \max }$ is equal to about $92 \%$ and $65 \%$ for $\mathrm{L}$ and $\mathrm{M}$ configuration, respectively;

- Monotonic and cyclic elastic stiffness exhibited similar values for both $\mathrm{L}$ and $\mathrm{M}$ configurations (3.00 and $3.49 \mathrm{kN} / \mathrm{mm}$ for L configuration and 5.25 and 5.25 for $\mathrm{M}$ configuration).

The data obtained from LVDTs make possible the evaluation of holddown stiffness and, in particular, three stiffnesses were evaluated: vertical stiffness $\mathrm{k}_{\mathrm{v}}$, horizontal stiffness $\mathrm{k}_{\mathrm{h}}$ and rotational stiffness $\mathrm{k}_{\mathrm{r}}$. The adding source of deformability $1 / \mathrm{k}_{\text {tot }}$ produced by hold-downs was evaluated, according to Equation 1, and it was in the range $2-3 \times 10^{-5}$.

$$
\text { Equation } 1
$$

$$
\frac{1}{k_{\text {tot }}}=\frac{1}{k_{1}+k_{2}+2 k_{h}}
$$

Where $\mathrm{k} 1$ and $\mathrm{k} 2$ are the adding source of global stiffnesses to vertical translation and rotation offered by hold-downs and are evaluated with Equation 2 and Equation 3.

$$
\begin{gathered}
\text { Equation } 2 \\
k_{1}=\frac{k_{r}}{h^{2}} \\
\text { Equation } 3 \\
k_{2}=\frac{L^{2}}{h^{2}} k_{v}
\end{gathered}
$$

Therefore, from the results, it can be assumed that hold-downs are rigid and offer a perfectly rigid restrain to the system.

Furthermore, through the local measurements given by SG, it was possible to evaluate the distribution of stresses and quantify the horizontal load absorbed by the frame and by the bracing. According to results, the contribution offered by the frame is really important, absorbing $50 \%$ of total horizontal load applied to the wall.

As far as inter-storey drift ratios are concerned, experimental values achieved were in the range $2.6 \%-6.8 \%$ and were always higher than design limit drift ratio considered (2.5\%). 

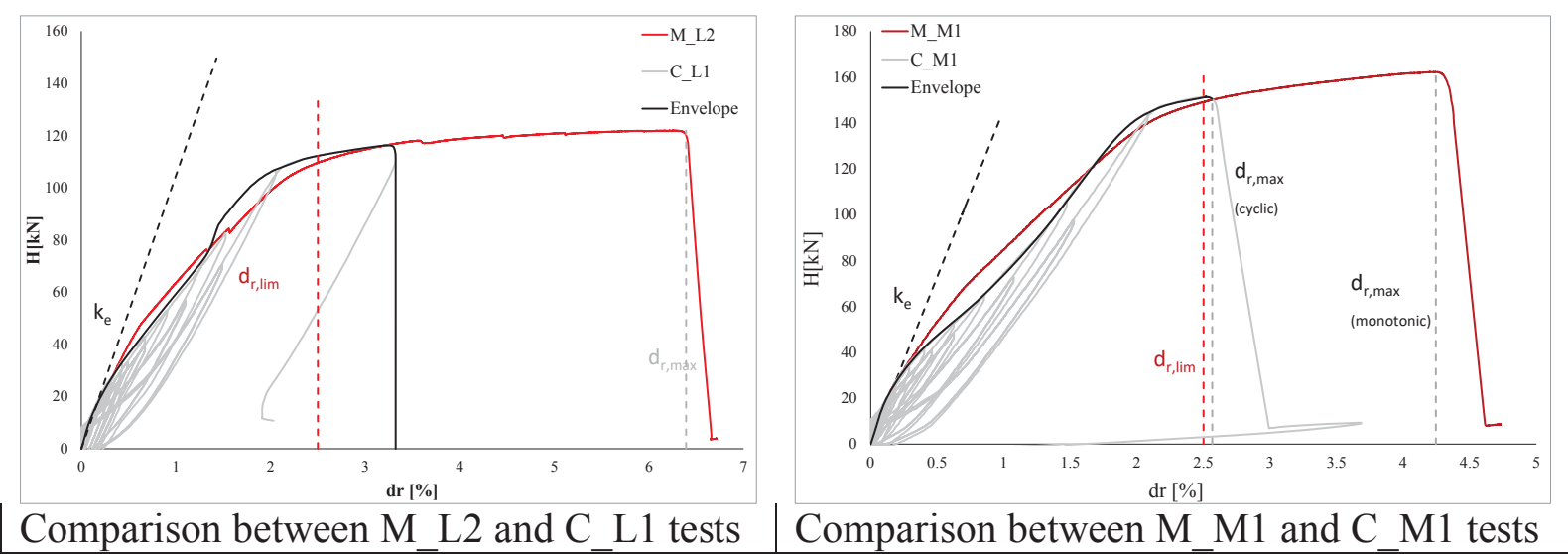

Figure 9 Comparison between monotonic and cyclic results

\section{TEST-BASED BEHAVIOUR FACTOR EVALUATION}

A preliminary experimentally based evaluation of behaviour factor was conducted. The behaviour factor $(q)$ was defined by the ductility-related $\left(R_{d}\right)$ and overstrength-related $\left(\mathrm{R}_{0}\right)$ modification factors.

In particular, the ductility-related modification factor $R_{d}$ represents the ability of the structural system to dissipate seismic energy, whereas the overstrength-related modification factor $\mathrm{R}_{0}$ represents the reserve of strength of the designed structure. The behaviour factor (q) can be estimated using Equation 4, as given in Uang [56]:

Equation 4

$$
q=R_{d} \cdot R_{0}
$$

Since fundamental periods for this structural system is generally in the range 0.1-0.5 s, the ductility-related force modification factor $R_{d}$ can be evaluated according to the principle of equal energy (Equation 5):

Equation 5

where $\mu$ is the ductility.

$$
R_{d}=\sqrt{2 \mu-1}
$$

The $\mathrm{R}_{0}$ factor can be evaluated through the formulation provided by Mitchell et al. [57]:

Equation 6

$$
R_{0}=R_{s d} \cdot R_{\varphi} \cdot R_{\text {yield }} \cdot R_{\text {sh }}
$$

where $\mathrm{R}_{\mathrm{sd}}=\mathrm{H}_{\mathrm{c}} / \mathrm{H}_{\mathrm{d}}$, with $\mathrm{H}_{\mathrm{c}}$ and $\mathrm{H}_{\mathrm{d}}$ design wall resistance and seismic demand, respectively;

$R_{\varphi}=\mathrm{H}_{\mathrm{yn}} / \mathrm{H}_{\mathrm{c}}$, with $\mathrm{H}_{\mathrm{yn}}$ design resistance associated by yielding of the braces multiplied by the safety factor $\gamma_{\mathrm{M} 0}$;

$\mathrm{R}_{\text {yield }}=\mathrm{H}_{\mathrm{y}} / \mathrm{H}_{\mathrm{yn}}$, with $\mathrm{H}_{\mathrm{y}}$ experimental yielding resistance;

$\mathrm{R}_{\mathrm{sh}}=\mathrm{H}_{\mathrm{p}} / \mathrm{H}_{\mathrm{y}}$, with $\mathrm{H}_{\mathrm{p}}$ experimental wall strength.

In order to neglect the design overstrength, in this study the assumption of $\mathrm{R}_{\mathrm{sd}}=\mathrm{H}_{\mathrm{c}} / \mathrm{H}_{\mathrm{d}}=1$ has been made. Therefore, the $\mathrm{R}_{0}$ factor can be evaluated through Equation 7:

Equation 7 


$$
R_{0}=\frac{H_{y n}}{H_{c}} \cdot \frac{H_{y}}{H_{y n}} \cdot \frac{H_{p}}{H_{y}}=\frac{H_{p}}{H_{c}}
$$

Table 4 shows the values of the behaviour factors obtained by the testbased evaluation. For the cyclic tests $\mathrm{R}_{0}, \mathrm{R}_{\mathrm{d}}$ and $\mathrm{q}$ were evaluated considering the average values in pushing and pulling phases. The test M_L1 was not considered since it showed a brittle premature failure. The average test-based values of behaviour factors are in the range of 3.09- 4.07 for the L Configuration and 3.67-4.07 for the M Configuration. On the safe side, it can be concluded that a value of behaviour factor equal to 3 can be assumed for the $\mathrm{L}$ configuration and a value equal to 2.5 for the M Configuration.

Table 4 Test-based evaluation of behaviour factor

\begin{tabular}{|c|c|c|c|c|}
\hline Test & M_L2 & M_M1 & C_L1 & C_M1 \\
$\mu$ & 5,42 & 4,99 & 3,61 & 2,95 \\
$\mathbf{R}_{\mathbf{d}}$ & 3,14 & 3,00 & 2,49 & 2,21 \\
$\mathbf{R}_{\mathbf{0}}$ & 1,30 & 1,22 & 1,24 & 1,14 \\
$\mathbf{q}$ & 4,07 & 3,67 & $\mathbf{3 , 0 9}$ & $\mathbf{2 , 5 3}$ \\
\hline
\end{tabular}

\section{CONCLUSIONS}

In the framework of an Italian research project, developed in cooperation with Lamieredil S.p.A. Company, an innovative wall system was developed and tested. The experimental tests were performed at the Laboratory of DIST (Department of Structures for Engineering and Architecture) of the University of Naples "Federico II". The experimental results showed satisfactory seismic responses, in line with the theoretical previsions, if all the prescriptions are followed. In particular, if not well designed, the nut used for the bar pretensioning can cause a premature failure of the system and the displacement capacity is strongly reduced. The walls, in which all the design prescriptions were respected, exhibited satisfactory force and displacement capacity.

\section{REFERENCES}

[1] R. Tartaglia, M. D'Aniello, M. Zimbru, Experimental and numerical study on the T-Stub behaviour with preloaded bolts under large deformations. Structures, 27, 2137-2155, 2020.

[2] R. Tartaglia, M. D’Aniello, M. Andreini, S. la Mendola, The performance of preloaded bolts in seismically prequalified steel joints in a fire scenario. Materials, 13(22), 1-14, 2020.

[3] R. Tartaglia, M. D’Aniello, R. Landolfo, Numerical simulations to predict the seismic performance of a 2-story steel momentresisting frame. Materials, 13(21), 1-17, 2020. 
[4] R. Tartaglia, M. D’Aniello, Influence of Transvserse Beams On the Ultimate Behaviour of Seismic Resistant Partial Strength BeamTo-Colummn Joints. Ingegneria Sismica, 37(3), 50-65, 2020.

[5] M. D'Aniello, R. Tartaglia, D. Cassiano, Experimental investigation of the inelastic tensile behaviour of non-preloadable grade 8.8 bolts. Ingegneria Sismica, 37(2), 92-109, 2020.

[6] R. Tartaglia, M. D'Aniello, G.A. Rassati, Proposal of AISCcompliant seismic design criteria for ductile partially-restrained endplate bolted joints. Journal of Constructional Steel Research,159, 364383, 2019.

[7] S. Costanzo, R. Tartaglia, G. Di Lorenzo, A. de Martino, Seismic behaviour of EC8-compliant moment resisting and concentrically braced frames. Buildings, 9(9), 196,2019.

[8] R. Tartaglia, M. D'Aniello, Nonlinear performance of extended stiffened end plate bolted beam-to-column joints subjected to column removal. Open Civil Engineering Journal, 11(M6), 369-383, 2017.

[9] R. Tartaglia, M. D'Aniello, A. de Martino, Ultimate performance of external end-plate bolted joints under column loss scenario accounting for the influence of the transverse beam. Open Construction and Building Technology Journal, 12, 132-139, 2018.

[10] R. Tartaglia, M. D’Aniello, G. Di Lorenzo, A. de Martino, Influence of EC8 rules on p-delta effects on the design and response of steel MRF. Ingegneria Sismica, 35(3), 104-120, 2018.

[11] R. Tartaglia, M. D’Aniello, G.A. Rassati, J.A. Swanson, R. Landolfo, Full strength extended stiffened end-plate joints: AISC vs recent European design criteria. Engineering Structures, 159,155-171, 2018 .

[12] G. Dell'Aglio, R. Montuori, E. Nastri, V. Piluso, Consideration of second-order effects on plastic design of steel moment resisting frames, Bulletin of Earthquake Engineering, 17 (6), 3041-3070, 2019

[13] V. Piluso, A. Pisapia, E. Nastri, R. Montuori, "Ultimate resistance and rotation capacity of low yielding high hardening aluminium alloy beams under non-uniform bending", Thin-Walled Structures, 135, 123-136, 2019.

[14] R. Montuori, E. Nastri, V. Piluso, "Problems of modeling for the analysis of the seismic vulnerability of existing buildings", Ingegneria Sismica, 36 (2), 53-85, 2019.

[15] R. Montuori, G. Gabbianelli, E. Nastri, M.Simoncelli, Rigid plastic analysis for the seismic performance evaluation of steel storage racks, Steel and Composite Structures, 32 (1), 1-19, 2019.

[16] F. Di Lauro, R. Montuori, E. Nastri, V. Piluso, Partial safety factors and overstrength coefficient evaluation for the design of connections equipped with friction dampers, Engineering Structures, 178, 645$655,2019$. 
[17] L. Fiorino, T. Pali, R. Landolfo. Out-of-plane seismic design by testing of non-structural lightweight steel drywall partition walls. Thin-Walled Structures, 130, 213-230, 2018. doi: 10.1016/j.tws.2018.03.032

[18] V. Macillo, S. Shakeel, L. Fiorino, R. Landolfo Development and Calibration of Hysteretic Model for CFS Strap braced stud walls. International Journal of Advanced Steel Construction, Hong Kong Institute of Steel Construction, 14(3), 337-360. 2018. doi: 10.18057/IJASC.2018.14.3.2

[19] L. Fiorino, V. Macillo, R. Landolfo, Experimental characterization of quick mechanical connecting systems for cold-formed steel structures. Advances in Structural Engineering, Multi-Science. ISSN 1369-4332, 20 (7), 1098-1110, 2017. doi:10.1177/1369433216671318

[20] L. Fiorino, O. Iuorio, V. Macillo, M.T. Terracciano, T. Pali, R. Landolfo. Seismic Design Method for CFS Diagonal Strap-Braced Stud Walls: Experimental Validation. Journal of Structural Engineering. ASCE. ISSN 0733-9445. 142(3), 04015154-1- 04015154-12: doi:10.1061/(ASCE)ST.1943-541X.0001408, 2016

[21] O. Iuorio, L. Fiorino, R. Landolfo.Testing CFS structures: The new school BFS in Naples. Thin-Walled Structures, Elsevier Science. ISSN 0263-8231. 84, 275-288, 2014. doi: 10.1016/j.tws.2014.06.006

[22] R. Landolfo, L. Fiorino, O. Iuorio.. A specific procedure for seismic design of cold-formed steel housing. Advanced Steel Construction, 6(1), 603-618, 2010.

[23] L. Fiorino,O. Iuorio, V. Macillo, R. Landolfo, Performancebased design of sheathed CFS buildings in seismic area, Thin-Walled Structures, 61, 248-257, 2012.

[24] L. Fiorino, O. Iuorio, R. Landolfo Seismic analysis of sheathing-braced cold-formed steel structures, Engineering Structures, 34, 538-547, 2012.

[25] L. Fiorino, O. Iuorio, R. Landolfo Sheathed cold-formed steel housing: A seismic design procedure. Thin-Walled Structures, 47(8-9), 919-930, 2009.

[26] A. Campiche, Innovative UHS steel material for tension-only braced CFS walls, Key Engineering Materials, 873, 25-31, 2021.

[27] ECCS. Recommended Testing Procedure for Assessing the Behaviour of Structural Steel Elements under Cyclic Loads, P045, ECCS Technical Committee 1 - Structural Safety and Loadings, Technical Working Group 1.3 - Seismic Design, European Convention fo, 1986.

[28] H. Krawinkler, P. Francisco, L. Ibarra, A. Ayoub, R. Medina, CUREE publication No. W-02 Development of a Testing Protocol for Woodrame Structures, 2001. 
[29] K. Velchev, G. Comeau, N. Balh, C.A. Rogers, Evaluation of the AISI S213 seismic design procedures through testing of strap braced cold-formed steel walls, Thin-Walled Struct. 48, 846-856, 2010. https://doi.org/10.1016/j.tws.2010.01.003.

[30] C. Uang, Establishing R (or Rw) and Cd Factors for Building Seismic Provisions, J. Struct. Eng., 117, 19-28, 1991. https://doi.org/10.1061/(ASCE)0733-9445(1991)117:1(19).

[31] D. Mitchell, R. Tremblay, E. Karacabeyli, P. Paultre, M. Saatcioglu, D.L. Anderson, Seismic force modification factors for the proposed 2005 edition of the National Building Code of Canada, Can. J. Civ. Eng., 30 () 308-327, 2003. https://doi.org/10.1139/102-111.

[32] 